\title{
PODE-SE IDENTIFICAR A PROPENSÃO E REDUZIR A EVASÃO DE ALUNOS? AÇÕES ESTRATÉGICAS E RESULTADOS TÁTICOS PARA INSTITUIÇÕES DE ENSINO SUPERIOR
}

\author{
GÉrSOn Tontini*; Silvana Anita Walter**
}

Recebido: 14 fev. 2012

Aprovado: 28 ago. 2012

* Universidade Regional de Blumenau. Blumenau, SC, Brasil. Contato: gersontontini@gmail.com

** Universidade Regional de Blumenau. Blumenau, SC, Brasil. Contato: silvanaanita.walter@gmail.com

Resumo: Este estudo desenvolve método de identificação do risco de evasão de alunos de graduação, o qual possibilita evidenciar, prever e diminuir fatores que influenciam esse risco, além de apresentar o resultado obtido por uma Instituição de Ensino Superior (IES). Por essa razão, possui caráter inovador. Nesta pesquisa, classificada como quantitativa, descritiva e do tipo levantamento, aplicou-se um questionário estruturado a 8.750 alunos de uma IES e, por meio de redes neurais artificiais e análise de cluster, identificaram-se os alunos em risco de evasão, os quais foram contatados e acompanhados pelos coordenadores de curso, o que contribuiu para uma redução de $18 \%$ no índice de evasão da IES. As dimensões que mais influenciaram a evasão foram colocação profissional e vocação do aluno, disponibilidade de tempo para estudo e fatores da vida pessoal. Como contribuição teórica, destaca-se a identificação de dimensões que influenciam a decisão de evasão ou permanência e o método desenvolvido, que pode auxiliar no desenvolvimento de novas pesquisas. No tocante às contribuições práticas, aponta-se que, a partir do método apresentado, as IES podem identificar alunos em risco de evasão e, assim, desenvolver estratégias e ações para que esses alunos permaneçam em seus estudos, caso assim o desejarem.

Palavras-chave: Estratégia em instituições de ensino superior. Evasão de alunos. Propensão. Redes Neurais Artificiais. Análise de Clusters.

\section{CAN STUDENTS' PROPENSITY TO DESERTION BE IDENTIFIED AND REDUCED? STRATEGIC ACTIONS AND TACTICAL RESULTS FOR HIGH EDUCATION INSTITUTIONS}

Abstract: This study develops a method for identification of risk of desertion of undergraduate students. It provides evidence to predict and reduce factors that influence this risk, and present the result obtained by a Higher Education Institution (HEI). In this study, classified as quantitative, descriptive and survey-type, we applied a structured questionnaire to 8,750 students. As a theoretical contribution, we highlight the identification of dimensions that influence the decision to drop out or stay and the proposed method, which can assist in the development of new researches. Students at risk of desertion were identified using artificial neural networks and cluster analysis. Using this diagnosis, the students in risk of desertion were contacted and followed by the program coordinators. It contributed to $18 \%$ reduction in the Institution's attrition rate. The dimensions with most influence were professional placement and vocation of the student, availability of time for study and personal life factors. Regarding practical contributions, it is noted that, from the presented method, the Institution can identify students at risk of desertion and thus develop strategies and actions for these students to remain in their studies if they wish.

Key words: Strategy in Higher Education Institutions. Attrition of Students.Propensity.Artificial Neural Networks. Cluster Analysis. 


\section{INTRODUÇÃO}

Desde o final dos anos de 1990, o governo federal e as instituições de ensino superior (IES) brasileiras buscam ampliar o acesso da população ao ensino superior. Nesse sentido, a partir de 1994, as IES privadas foram incentivadas a ampliar as vagas ofertadas e, após 2002, passaram a ser ampliadas, também, as vagas nas IES públicas. Assim, o contexto revela que o ambiente da educação superior caracteriza-se, entre outros aspectos, por uma crescente competitividade entre essas instituições na busca por alunos, recursos e prestígio.

O incentivo ao aumento de vagas e a consequente ampliação do número de pessoas com nível superior - de 4,4\% para 7,9\% segundo o IBGE (2012) - constituíram uma iniciativa importante para o desenvolvimento do país, não obstante o aumento de ofertas de vagas, principalmente nas IES privadas, tenha sido mais amplo que o aumento do número de ingressantes. Por sua vez, a queda no número de ingressantes, associada ao aumento do número de vagas ofertadas, tem ampliado a ociosidade das IES, conforme aponta o percentual de preenchimento de vagas de ingresso em 2009, que foi de $42 \%$ (INEP, 2009).

Por outro lado, têm-se os índices de evasão, que são costumeiramente mais amplos nas IES privadas. Os dados publicados pelo INEP mostram que o conjunto de IES privadas apresenta, anualmente, em torno de $20 \%$ de evasão. Desses fatores decorrem consequências negativas para a manutenção da qualidade de ensino e para a sobrevivência dessas IES. Como destacam Silva Filho et al. (2007), a evasão se torna um desperdício social, acadêmico e econômico. Para a instituição, acarreta ociosidade do espaço físico, de professores, de funcionários e de equipamentos, o que, nas instituições públicas, se reflete em desperdícios dos investimentos do governo e, nas particulares, redução no recebimento de mensalidade. Para os estudantes, por sua vez, a evasão pode representar o atraso ou cancelamento de um sonho, perda de oportunidades de trabalho, de crescimento pessoal e de melhoria de renda, entre muitas outras consequências. Diante de tal contexto, pergunta-se: o que leva alunos a se evadirem?

$\mathrm{Na}$ literatura, pode-se identificar como resposta a esse questionamento que a evasão pode estar relacionada a fatores institucionais, pessoais e externos. No que tange aos fatores indutores à evasão de alunos de ensino superior, estudos têm sido amplamente publicados internacionalmente. Porém, poucos deles foram realizados para elucidar a importância dessas diferentes dimensões e seu impacto em estudantes de IES do Brasil, o que justifica a necessidade de aprofundar alguns questionamentos, tais como: Quais dimensões levam os alunos de cursos de graduação a se evadirem e qual o impacto de cada dimensão na evasão? 
Embora já existam estudos sobre quais fatores levam um aluno a se evadir, não se encontraram, na literatura nacional ou internacional, estudos que tenham procurado identificar métodos que possam auxiliar as IES no diagnóstico do real risco de evasão. Além disso, o número de IES brasileiras que desenvolveu programas institucionalizados de combate à evasão é incipiente (SILVA FILHO et al, 2007). Diante dessa lacuna, este estudo apresenta a seguinte pergunta central de pesquisa: Como identificar fatores que influenciam o risco de evasão dos alunos de cursos de graduação em uma IES? A importância desse estudo reside no fato de que, ao se identificarem os alunos mais propensos a abandonarem seus cursos, é possível desenvolver estratégias para que tais alunos permaneçam em seus estudos, caso assim o desejarem.

Outro aspecto apresentado pelas pesquisas sobre evasão de alunos é que não costumam especificar o quanto essa identificação pode reduzir a evasão de tais alunos. Assim, mais uma pergunta permanece: Qual redução de evasão é possível se obter por meio da identificação da propensão à evasão dos alunos?

Visando, então, responder às perguntas até o momento apresentadas, o presente trabalho tem como objetivos: a) identificar o impacto das dimensões de tendência na evasão prevista e na ocorrida; b) verificar como alguns métodos de identificação do risco de evasão de alunos de graduação possibilitam evidenciar, prever e diminuir fatores que influenciam o risco de evasão dos alunos desses cursos; c) apresentar o resultado em redução de evasão pela aplicação desses métodos na identificação sobre a propensão à evasão de alunos no semestre seguinte.

Expõe-se tal pesquisa neste artigo, o qual se encontra organizado em mais quatro seções além desta primeira. A segunda seção aborda as pesquisas científicas sobre as dimensões relacionadas à evasão de alunos no Ensino Superior; na terceira seção, apresenta-se o delineamento metodológico da pesquisa; na quarta, discutem-se os resultados; e, na quinta, expõem-se as considerações finais, implicações gerenciais e limitações do estudo.

\section{ASPECTOS RELACIONADOS À EVASÃO}

Diferentes fatores relacionados à decisão dos alunos de ensino superior de permanecerem em seu curso ou de se evadirem do mesmo podem ser encontrados na literatura. Alguns desses fatores estão relacionados a aspectos internos, de responsabilidade da IES. Tais antecedentes da evasão ou da permanência podem estar relacionados a percepções referentes ao curso, aos seus conteúdos e aos seus professores. Cislaghi (2008), por exemplo, destaca que o abandono 
da universidade pode estar relacionado à percepção que o aluno possui sobre a qualidade do curso que frequenta. Albuquerque (2008), por sua vez, sugere que alunos que iniciam um curso que não era sua primeira opção de escolha e nele decidiram permanecer, o fizeram por ficarem satisfeitos com a qualidade do contexto universitário no tocante à organização e à atuação dos docentes, bem como por ficarem positivamente surpresos com o curso, em especial com aspectos relacionados a componentes práticos. Já Moraes e Theóphilo (2006) identificaram, como um dos motivos de evasão, a forma de ministrar as disciplinas do curso, no sentido de não atender às expectativas dos alunos. Sob essa ótica, Rollo e Pereira (2003) destacam a importância da percepção que os alunos possuem a respeito da competência e habilidades didáticas dos professores na decisão de permanecer ou deixar o curso. Spinosa (2003) também se manifesta a respeito, ressaltando a importância de as IES possuírem políticas voltadas para a permanência dos estudantes, incluindo ações de modernização de métodos e currículos.

Outro tipo de percepção que pode influenciar a decisão de deixar ou não a IES é a que o aluno possui sobre o atendimento a ele prestado. Como indica Albuquerque (2008), em sua pesquisa, a permanência foi influenciada pelos serviços e programas disponibilizados aos estudantes. Nessa mesma direção, Tinto (2002) considera que aconselhamento e apoio são condições importantes de suporte à persistência de estudantes no ensino superior, especialmente aos que estão no seu primeiro ano.

Tem-se, ainda, a percepção concernente à infraestrutura da IES, pois as deficiências nas estruturas físicas das universidades são apontadas como um dos fatores que interferem nos índices da evasão (DIAS; THEÓPHILO; LOPES, 2010). Essas estruturas incluem qualidade do espaço físico em geral, da sala de aula, dos laboratórios, dos equipamentos e da biblioteca.

Outros antecedentes da evasão no ensino superior que podem ser observados na literatura são os vinculados aos resultados obtidos pelos alunos a partir do curso de graduação, os quais podem ser tanto em relação ao momento presente (como aprendizado, desenvolvimento e desempenho), quanto ao futuro (como atuação profissional e melhoria das condições de vida). A esse respeito, Tinto (2002) destaca a promoção da aprendizagem; Spady (1970), o desenvolvimento intelectual que os alunos percebem a partir do curso e as avaliações de desempenho; e Pascarella (1980), resultados educacionais (notas obtidas pelo aluno, crescimento pessoal e intelectual, bem como integração). A importância do desempenho obtido pelos alunos também é destacada por Allen et al. (2008) e Cislaghi (2008). Moraes e Theóphilo (2006) apresentam as dificuldades dos 
alunos em relação ao conteúdo de alguma(s) disciplina(s), o que poderia ser amenizado pelo curso e pela IES por meio da oferta de reforço escolar.

Leppel (2005), por sua vez, aponta que estudantes que esperam ser bemsucedidos julgam o curso, muitas vezes, por meio das possibilidades de ganhos futuros. Em relação a isso, segundo Santos (2001), entre os fatores que podem influenciar o ato de evasão, estão as oportunidades profissionais. Albuquerque (2008) acrescenta o receio de não conseguir trabalhar na área profissional quando concluído o curso. Hotza (2000) verificou, ainda, que a concentração de abandono nas primeiras fases poderia ser justificada pela decepção com as expectativas positivas e com a possibilidade de exercer a carreira escolhida. Como destaca Augustin (2005), muitas vezes, é transmitida ao jovem uma visão negativa do mercado de trabalho e da profissão, de forma que o mesmo fica confuso e acaba se evadindo do curso. Essas possibilidades de atuação profissional são importantes também porque, de acordo com Oliveira e Bittar (2010), muitos alunos esperam que o estudo possa melhorar suas condições de vida.

Do mesmo modo, integração do estudante com outras pessoas da instituição é um antecedente da permanência apontado na literatura. Spady (1970) destaca o suporte em amizades; Pascarella (1980), o nível de contato informal entre estudante e professores e o convívio universitário dentro e fora de aula; Santos (2001), o processo de integração; Allen et al. (2008), a relação com colegas e professores; Albuquerque (2008), as interações estabelecidas entre os estudantes e os membros da comunidade universitária; e Cislaghi (2008), relacionamentos e integração acadêmica. Essa participação e esse envolvimento do acadêmico com os professores, funcionários e com outros alunos são, de acordo com Tinto (2002), um importante preditor da permanência, principalmente no primeiro ano de graduação.

A identificação e o comprometimento do aluno com o curso escolhido também se relaciona com a decisão de permanecer na graduação ou não. A escolha do curso, de acordo com Dowd e Coury (2006), afeta a retenção de alunos, além de, segundo Albuquerque (2008), a entrada em um curso de graduação ocorrer muitas vezes por eliminação de outras possibilidades, e não pela escolha do curso de maior interesse. Santos (2001) e Moraes e Theóphilo (2006) também identificaram a falta de vocação para o curso como um dos fatores que pode influenciar a evasão. Para Leppel (2001), a afinidade do aluno com o curso influencia a sua motivação e tem como consequência a sua permanência. O compromisso com a instituição e a percepção de utilidade da formação são outros fatores que podem pesar na decisão de permanecer no curso (CISLAGHI, 2008). 
Para permanecer estudando, os alunos igualmente necessitam de condições favoráveis, pois, do contrário, serão impelidos a desistir do curso. As dificuldades para conciliar trabalho e estudo foram identificadas nos estudos de Correa, Noronha e Miura (2004) e de Moraes e Theóphilo (2006). Essa necessidade de trabalhar está relacionada a outro fator: as condições financeiras pessoais e familiares. A esse respeito, Allen et al. (2008) apontam que estudantes de nível socioeconômico mais elevado estavam mais predispostos a permanecer, enquanto Dowd e Coury (2006) indicam que, quando a situação financeira do aluno é desfavorável, reduz a possibilidade de o mesmo permanecer na IES. Cabrera, Nora e Castañeda (1992) acrescentam que, contando com suporte financeiro, o estudante sofre menos ansiedade e estresse. Assim, segundo Spinosa (2003), é importante que existam políticas voltadas para a permanência dos estudantes nas universidades, como o fortalecimento de apoio financeiro.

Identificou-se, ainda, na literatura, que características pessoais dos estudantes podem influenciar sua decisão de permanecer ou não na IES. Albuquerque (2008), por exemplo, indica que os aspectos familiares, assim como problemas de saúde, foram identificados nas pesquisas de Corrêa, Noronha e Miura (2004) e de Dias, Theóphilo e Lopes (2010). A motivação do estudante (seu interesse e percepção de valor), de acordo com Ruiz (2003), afeta o grau de esforço do estudante no curso e sua persistência. A motivação, conforme aponta Cislaghi (2008), também está relacionada com o compromisso do aluno em relação as suas metas e objetivos, sendo que esse compromisso exerce influência positiva sobre a permanência do estudante (HENING-THURAU; LANGER; HANSEN, 2001; ANJOS NETO; MOURA, 2004).

\section{DELINEAMENTO METODOLÓGICO}

Para atingir os objetivos propostos neste estudo, realizou-se uma pesquisa quantitativa, de caráter descritivo, do tipo levantamento. $\mathrm{O}$ instrumento utilizado para coleta de dados foi um questionário estruturado, que, orientado pela literatura, explora a percepção referente aos atributos de retenção dos alunos matriculados nos cursos de graduação da Fundação Universidade Regional de Blumenau (FURB) e cuja validação se deu por meio de consulta a especialistas da área. Para identificar os índices de evasão dos alunos, realizou-se pesquisa documental nos índices de evasão de alunos de relatórios da universidade de 2005 a 2010.

Aplicou-se o questionário em dois semestres - 2009/1 e 2009/2 - a uma população composta por todos os alunos matriculados (10.550) em todos os 37 cursos da universidade durante o segundo semestre do ano de 2009, o que 
caracteriza a pesquisa como um censo. Aplicou-se o questionário via on-line a todos os alunos da instituição presentes em sala de aula ao final do segundo semestre. Para o processamento dos dados, excluíram-se os alunos do curso de medicina, por terem baixíssimo índice de evasão. Analisaram-se os dados coletados ao final de 2009, juntamente com as respostas de 600 alunos aos questionários aplicados durante o final do primeiro semestre de 2009, dos quais 300 permanceram no segundo semestre e 300 se evadiram. Efetuou-se a inclusão de dados do semestre anterior para que se tivessem, no processamento, amostras de alunos que vieram a se evadir posteriormente e de alunos que não vieram a se evadir. No total, obtiveram-se 8.957 casos. Após o tratamento dos dados, excluíram-se 215 casos com respostas inconsistentes ou inválidas, perfazendo 8.750 casos válidos.

Como possíveis antecedentes da evasão, avaliou-se o desempenho de 34 questões referentes a atributos extraídos da literatura, conforme apresentado no Quadro 1. Cada respondente apontou seu nível de concordância em uma escala intervalar que variou de 1 (discordo totalmente) a 5 (concordo totalmente). Analisou-se, também, mais uma dimensão relacionada à propensão à permanência, ou seja, analisaram-se as intenções de continuidade do aluno no semestre seguinte e de se formar sem interrupções.

Após coletados os dados, como primeiro passo, efetuou-se a análise fatorial utilizando o método de extração de componentes principais e método de rotação Varimax com normalização Kaiser. Também se empregou o Alfa de Cronbach para analisar a confiabilidade das dimensões geradas a partir da análise fatorial (HAIR JR. et al., 2007). Como resultado da análise fatorial, obtiveram-se 8 dimensões: a) qualidade de curso; b) colocação profissional e vocação; c) conservação da infraestrutura; d) vida pessoal; e) atendimento na IES; f) tempo para estudo; g) situação financeira; e h) necessidade de reforço. Sintetizaram-se as respostas de cada aluno nessas dimensões, que foram utilizadas em conjunto com informações descritivas pessoais nos métodos seguintes.

Para o primeiro objetivo, analisar o impacto das dimensões específicas na propensão à evasão, realizou-se a análise de correlação de Pearson, na qual se utilizaram como variáveis de controle: turno, tipo de curso (sociais, educação, sociais aplicadas, tecnologia ou saúde), fase (semestre em curso), existência de apoio financeiro da empresa em que trabalha e se trabalha na área do curso que está frequentando. Verificou-se a correlação entre a tendência do aluno a permanecer e as 8 dimensões sintetizadas, como também a correlação entre o aluno ter se evadido ou não no ano de 2010/1 (com valor 0, para evadido, e 1, para que permaneceu) e as mesmas 8 dimensões. 


\section{Quadro 1 - Antecedentes da evasão avaliados}

\begin{tabular}{|c|c|}
\hline $\begin{array}{l}\text { Antecedentes da evasão ou } \\
\text { da permanência }\end{array}$ & Origem teórica \\
\hline Qualidade do curso & Cislaghi (2008) e Moraes e Theóphilo (2006) \\
\hline Organização do curso & Albuquerque (2008) \\
\hline Atualização do curso & Spinosa (2003) \\
\hline Relação entre teoria e prática & \multirow{2}{*}{ Albuquerque (2008) } \\
\hline Aplicação profissional do aprendizado & \\
\hline Competência dos professores & Rollo e Pereira (2003) e Albuquerque (2008) \\
\hline Atendimento do curso & \multirow{4}{*}{ Albuquerque (2008) } \\
\hline Atendimento da coordenação & \\
\hline Atendimento do centro & \\
\hline Atendimento da praça de alimentação & \\
\hline Qualidade dos laboratórios & \multirow{5}{*}{ Dias, Theóphilo e Lopes (2010) } \\
\hline Conservação das salas de aula & \\
\hline Conservação da infraestrutura & \\
\hline Limpeza e conservação dos banheiros & \\
\hline Equipamentos em salas de aula & \\
\hline Aprendizado com o curso & Tinto (2002) \\
\hline Desenvolvimento pessoal & Spady (1970) e Pascarella (1980) \\
\hline Obtenção de boas notas e/ou conceitos & $\begin{array}{l}\text { Spady (1970), Pascarella (1980), Moraes e } \\
\text { Theóphilo (2006), Allen et al. (2008) e Cislaghi } \\
\text { (2008) }\end{array}$ \\
\hline Necessidade de reforço de aulas & Moraes e Theóphilo (2006) \\
\hline Oportunidades profissionais & $\begin{array}{l}\text { Hotza (2000), Santos (2001), Augustin (2005) e } \\
\text { Albuquerque (2008) }\end{array}$ \\
\hline Perspectivas de melhoria de vida & Leppel (2005) e Oliveira e Bittar (2010) \\
\hline Integração com a turma & $\begin{array}{l}\text { Spady (1970), Pascarella (1980), Santos (2001), } \\
\text { Tinto (2002), Allen et al. (2008), Albuquerque (2008) } \\
\text { e Cislaghi (2008) }\end{array}$ \\
\hline Escolha do curso & $\begin{array}{l}\text { Leppel (2001), Down e Coury (2006) e Albuquerque } \\
\text { (2008) }\end{array}$ \\
\hline Identificação com o curso & $\begin{array}{l}\text { Leppel (2001), Santos (2001), Moraes e Theóphilo } \\
\text { (2006) e Albuquerque (2008) }\end{array}$ \\
\hline Importância profissional do curso & Albuquerque (2008) e Cislaghi (2008) \\
\hline Comprometimento com o curso & Leppel (2001) e Cislaghi (2008) \\
\hline Tempo disponível para o estudo & $\begin{array}{l}\text { Moraes e Theóphilo (2006) e Corrêa, Noronha e } \\
\text { Miura (2004) }\end{array}$ \\
\hline Disponibilidade para frequentar as aulas & Moraes e Theóphilo (2006) \\
\hline Suficiência de renda pessoal ou familiar & $\begin{array}{l}\text { Cabrera, Nora e Castañeda (1992), Down e Coury } \\
(2006) \text {, Moraes e Theóphilo (2006) e Allen et al. } \\
(2008)\end{array}$ \\
\hline Necessidade bolsa de estudo & Spinosa (2003) \\
\hline Estabilidade pessoal e familiar & Albuquerque (2008) \\
\hline Saúde pessoal & $\begin{array}{l}\text { Corrêa, Noronha e Miura (2004) e Dias, Theóphilo } \\
\text { e Lopes (2010) }\end{array}$ \\
\hline Motivação para vida & Ruiz (2003) e Cislaghi (2008) \\
\hline Persistência pessoal nos objetivos & $\begin{array}{l}\text { Hening-Thurau, Langer e Hansen (2001) e Anjos } \\
\text { Neto e Moura (2004) e Cislaghi (2008) }\end{array}$ \\
\hline
\end{tabular}

Fonte: Os autores. 
Para identificação do risco de evasão dos alunos, analisaram-se os dados por meio de Radial Basis Function Neural Networks, ou Redes Neurais Artificiais do tipo RBF. Igualmente se fez a análise de cluster.

A análise de agrupamento de cluster procura classificar um conjunto de objetos (alunos), formando grupos por similaridade. Para tanto, usa as respostas de determinado grupo às perguntas sem que seja necessário definir critérios que classifiquem os dados que integram esse grupo (AAKER; KUMAR; DAY, 2001). No caso dos alunos em risco de evasão, procurou-se agrupar por semelhança os alunos evadidos e os não evadidos. Para a formação desses grupos, utilizou-se o método aglomerativo, em que cada objeto (respondente) parte como sendo um cluster, e, nos passos subsequentes, os dois objetos mais próximos se agregam num só cluster (HAIR JR. et al., 2007). Efetuou-se a análise de cluster utilizando-se a propensão dos alunos à evasão, a síntese das respostas de acordo com as dimensões da análise fatorial e se os alunos se evadiram ou não entre 2009/1 e 2009/2.

As redes neurais artificiais são assim denominadas por serem compostas por uma rede de funções matemáticas, simulando neurônios. As redes neurais com funções de bases radiais "são funcionalmente equivalentes a sistemas de inferência por lógica difusa" (TONTINI; QUEIROZ, 1996, p. 1.366). São divididas em três camadas de "neurônios artificiais" (Figura 1), sendo que a rede de entrada distribui as informações à camada interna e a saída dos nós da camada intermediária é calculada por uma função gaussiana.

Figura 1 - Rede Neural Artificial (RBF)

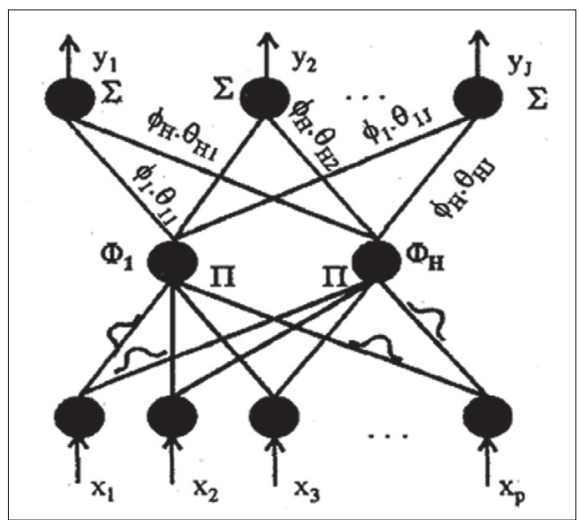

Fonte: TONTINI, Gérson; QUEIROZ, Abelardo A. RBF Fuzzy-ARTMAP: a new neural network for robust on-line learning and identification of patterns. In: IEEE INTERNATIONAL CONFERENCE ON SYSTEMS, MAN AND CYBERNETICS. Proceedings... Beijing, 1996. p. 1366. 
Realizou-se treinamento da rede RBF pela apresentação à mesma do comportamento dos dados de alunos que se evadiram e do comportamento dos dados de alunos que não se evadiram. Nesse tipo de treinamento, dois passos são realizados: inicialmente, a camada intermediária é treinada usando o método de cluster k-means (MOODY; DARKEN, 1989) ou o método de aproximação sucessiva (LINKENS; NIE, 1993) e, posteriormente, a camada de saída é treinada por métodos, como mínimo quadrado ou gradiente descente. Após o treinamento, um conjunto de dados é apresentado para verificar a eficiência do aprendizado. Utilizaram-se, como entradas da rede RBF, as respostas dos alunos nas dimensões sintetizadas pela análise fatorial. Além dessas, se fez uso das respostas a perguntas sobre se estava trabalhando no momento de resposta ao questionário, se recebia apoio financeiro da empresa onde estava trabalhando, semestre/fase que estava estudando, área do curso em que estava matriculado (sociais, educação, sociais aplicadas, tecnologia ou saúde), propensão a responder o questionário e, ainda, o diagnóstico de risco à evasão pelo método de cluster. Uma vantagem de redes neurais artificiais é que não há limitação quanto ao tipo de respostas para processamento (ordinais, variáveis, semânticas, etc.).

Após a identificação dos alunos propensos à evasão, se fez o repasse do nome desses alunos aos coordenadores de curso, juntamente com a instrução de efetuarem contato com os mesmos, convidando-os para conversar, visando estimular sua permanência na instituição.

\section{ANÁLISE E RESULTADOS}

Nesta seção, apresentam-se os resultados obtidos e faz-se a análise dos mesmos. O resultado da análise fatorial (Tabela 1) resultou em 8 dimensões denominadas: qualidade de curso; colocação profissional e vocação; conservação da infraestrutura; vida pessoal; atendimento na IES; tempo para estudo; situação financeira; e necessidade de reforço.

Os resultados do Alfa de Cronbach revelam 6 dimensões acima de 0,6 ou 0,7. Cabe elucidar que o limite inferior aceito para o Alfa de Cronbach é de 0,70, podendo diminuir para 0,60 em pesquisas exploratórias e que um coeficiente Alfa de Cronbach maior que 0,70 demonstra um bom grau de confiabilidade (HAIR JR. et al., 2007). Os índices altos do Alfa de Cronbach obtidos mostram a consistência das variáveis indicadoras em relação às suas variáveis latentes (dimensões/construto). Das 6 dimensões identificadas, duas apresentaram alfa abaixo do recomendado: tempo para estudo e necessidade de reforço. Contudo, mantiveram-se tais dimensões no modelo por serem teoricamente suportadas. 
Tabela 1 - Rotação dos Antecedentes da propensão à evasão

\begin{tabular}{|c|c|c|c|c|c|c|c|c|}
\hline \multirow{3}{*}{ Variáveis } & \multicolumn{8}{|c|}{ Componentes } \\
\hline & 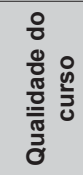 & 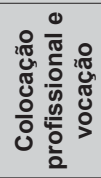 & 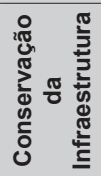 & $\begin{array}{l}\bar{\pi} \\
0 \\
0 \\
0 \\
0 \\
0 \\
\frac{\pi}{0} \\
:\end{array}$ & 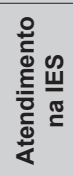 & 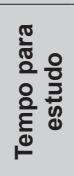 & 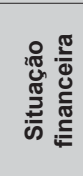 & 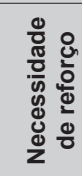 \\
\hline & 1 & 2 & 3 & 4 & 5 & 6 & 7 & 8 \\
\hline Qualidade do curso & 0,74 & & & & & & & \\
\hline Atualização do curso & 0,72 & & & & & & & \\
\hline Organização do curso & 0,71 & & & & & & & \\
\hline Competência dos professores & 0,67 & & & & & & & \\
\hline Relação entre teoria e prática & 0,60 & & & & & & & \\
\hline Atendimento da coordenação & 0,54 & & & & & & & \\
\hline Qualidade dos laboratórios & 0,51 & & & & & & & \\
\hline Escolha do curso & & 0,73 & & & & & & \\
\hline Identificação com o curso & & 0,70 & & & & & & \\
\hline Perspectivas de melhoria de vida & & 0,63 & & & & & & \\
\hline Desenvolvimento pessoal & & 0,54 & & & & & & \\
\hline Oportunidades profissionais & & 0,54 & & & & & & \\
\hline Importância do curso & & 0,53 & & & & & & \\
\hline Comprometimento com curso & & 0,53 & & & & & & \\
\hline Aplicação profissional do aprendizado & & 0,51 & & & & & & \\
\hline Conservação das salas de aula & & & 0,80 & & & & & \\
\hline Conservação da infraestrutura & & & 0,78 & & & & & \\
\hline Limpeza e conservação dos banheiros & & & 0,77 & & & & & \\
\hline Equipamentos em salas aula & & & 0,59 & & & & & \\
\hline Estabilidade pessoal e familiar & & & & 0,70 & & & & \\
\hline Motivação para vida & & & & 0,68 & & & & \\
\hline Saúde pessoal & & & & 0,67 & & & & \\
\hline Persistência nos objetivos & & & & 0,64 & & & & \\
\hline Atendimento do curso & & & & & 0,78 & & & \\
\hline Atendimento do centro & & & & & 0,71 & & & \\
\hline Atendimento da praça de alimentação & & & & & 0,59 & & & \\
\hline Tempo disponível para o estudo & & & & & & 0,69 & & \\
\hline Disponibilidade para frequentar as aulas & & & & & & 0,67 & & \\
\hline Integração com a turma & & & & & & 0,56 & & \\
\hline Necessidade bolsa de estudo & & & & & & & 0,83 & \\
\hline Suficiência de renda pessoal ou familiar & & & & & & & $-0,78$ & \\
\hline Necessidade de reforço de aulas & & & & & & & & 0,77 \\
\hline Obtenção de boas notas e/ou conceitos & & & & & & & & $-0,54$ \\
\hline Alfa Cronbach & 0,84 & 0,85 & 0,79 & 0,71 & 0,71 & 0,46 & 0,64 & 0,33 \\
\hline \% Variância Explicada & $12 \%$ & $23 \%$ & $31 \%$ & $38 \%$ & $43 \%$ & $48 \%$ & $53 \%$ & $56 \%$ \\
\hline
\end{tabular}

Método de Extração: Análise de Componentes Principais. Método de Rotação: Varimax com Normalização Kaiser.

Fonte: Dados da pesquisa. 
Para a dimensão evasão, realizou-se uma nova rotação, com as questões específicas relacionadas à propensão à permanência. Para essa dimensão, o Alfa Cronbach atingiu o índice de 0,513 , tendo sido analisadas as variáveis: a) continuarei estudando na IES no próximo semestre e; b) me formarei, na IES, sem interrupções pelo caminho.

\subsection{Impacto das dimensões pesquisadas na propensão e na evasão}

Para verificar o que é relevante no contato dos coordenadores dos cursos da instituição com os alunos que apresentam propensão à permanência/evasão, torna-se importante averiguar a relação de cada dimensão nessa propensão. Isso possibilita uma análise mais específica das questões relacionadas à evasão, o que servirá de subsídio ao contato efetuado pelos coordenadores.

A Tabela 2 e a Figura 2 apresentam a correlação entre as dimensões estudadas e a propensão do aluno de permanecer (2009/2), bem como a correlação entre as dimensões e o fato de o aluno se evadir ou permanecer no semestre seguinte (2010/1). Utilizou-se como variáveis de controle: o tempo/período cursado (fase), o tipo de curso, o turno, a existência de apoio financeiro da empresa na qual trabalha e a atuação profissional na área do curso.

Tabela 2 - Dimensões de influência sobre o risco de evasão e sobre a evasão

\begin{tabular}{lcccc}
\hline \multicolumn{1}{c}{ Dimensões } & $\begin{array}{c}\text { Tendência a } \\
\text { permanecer } \\
(\mathbf{2 0 0 9 / 2 )}\end{array}$ & p-value & $\begin{array}{c}\text { Permanência em } \\
(\mathbf{2 0 1 0 / 1 )}\end{array}$ & p-value \\
\hline Colocação profissional e vocação & $0,36^{*}$ & 0,00 & $0,06^{*}$ & 0,00 \\
\hline Vida pessoal & $0,34^{*}$ & 0,00 & $0,03^{*}$ & 0,01 \\
\hline Qualidade do curso & $0,17^{*}$ & 0,00 & $-0,02$ & 0,10 \\
\hline Conservação da infraestrutura & $0,12^{*}$ & 0,00 & $-0,04^{*}$ & 0,00 \\
\hline Tempo para estudo & $0,08^{*}$ & 0,00 & $0,04^{*}$ & 0,00 \\
\hline Atendimento na IES & $0,07^{*}$ & 0,00 & 0,00 & 0,75 \\
\hline Situação financeira & 0,02 & 0,09 & $-0,01$ & 0,41 \\
\hline Necessidade de reforço & 0,01 & 0,37 & $-0,04^{*}$ & 0,00 \\
\hline * correlação com significância estatística $(p-v a l u e<0,05)$ & & \\
\hline
\end{tabular}

Fonte: Dados da pesquisa. 
Figura 2 - Impacto das dimensões na propensão e na real evasão dos alunos

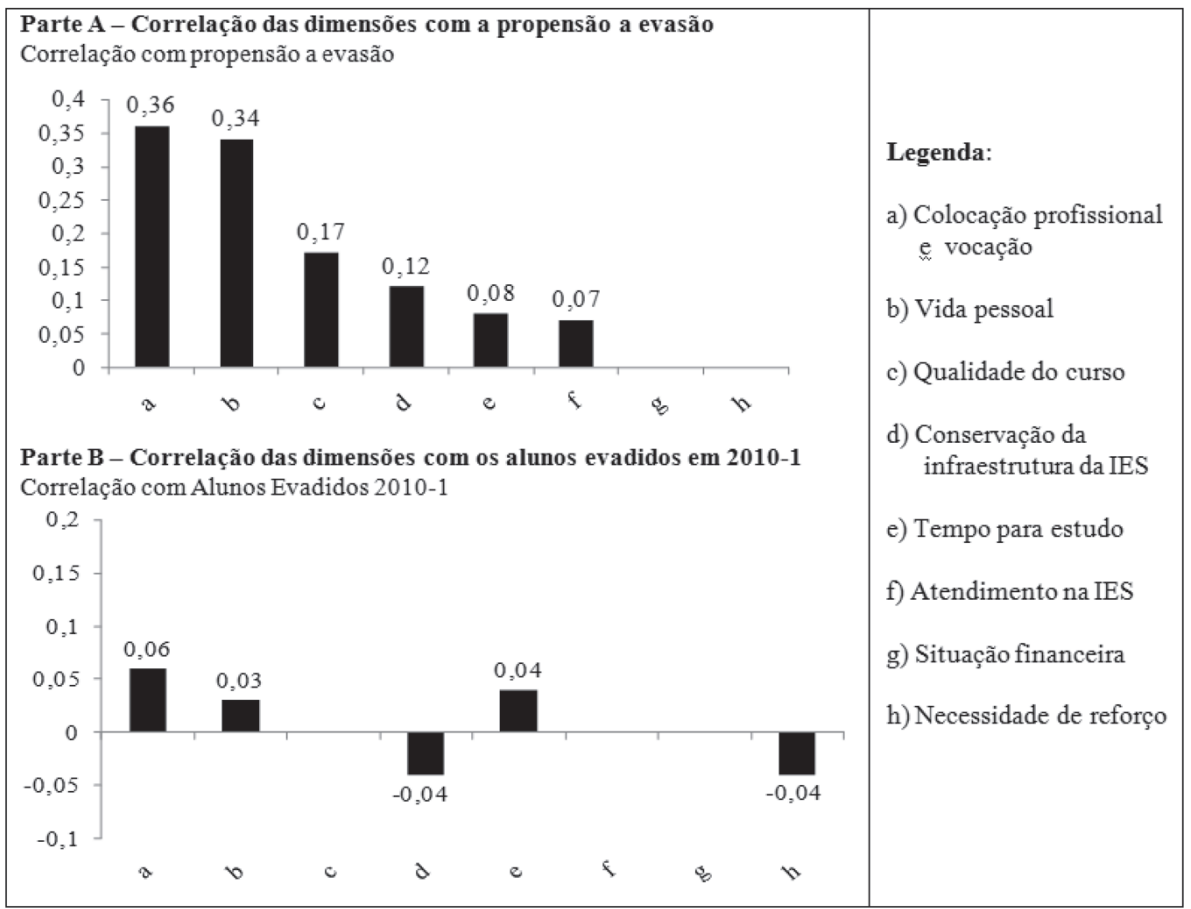

Fonte: Dados da pesquisa.

Percebe-se, por meio da Tabela 2 e da Figura 2, que, tanto para a tendência a permanecer, quanto para os alunos que se evadiram, a dimensão com maior influência foi a colocação profissional e vocação. As variáveis que compõem esta dimensão, em ordem decrescente em termos de impacto, são: escolha do curso, identificação com o curso, perspectivas de melhoria de vida e aprendizado com o curso, seguidos por desenvolvimento pessoal, oportunidades profissionais, importância profissional do curso, comprometimento pessoal com o curso e aplicação profissional do aprendizado. A importância atribuída pelos alunos aos fatores obtidos permite que a IES pesquisada levante algumas questões: o que fazer para auxiliar os alunos com sua vocação perante os cursos que estão frequentando? E no que a IES pode auxiliar para a atual e futura colocação profissional dos alunos?

Ainda em referência ao risco de evasão, se destaca a dimensão vida pessoal, que inclui estabilidade pessoal e familiar, motivação para vida, saúde pessoal e persistência nos objetivos. Embora tal aspecto esteja fora do controle interno, a 
IES pode se perguntar: o que fazer para auxiliar um aluno quanto a problemas pessoais?

Quanto à dimensão com segunda maior influência sobre a real evasão ou não, os resultados apontaram o tempo para estudo, ou seja, os alunos que vêm a se evadir têm menor tempo disponível para estudo. Essa dimensão integra tempo disponível para o estudo, disponibilidade para frequentar as aulas e, em menor impacto, integração com a turma e é a dimensão na qual a IES menos pode ajudar o aluno.

O terceiro maior impacto na propensão do aluno a se evadir ocorreu na dimensão sobre questões relacionadas à qualidade do curso. Embora tenha menor impacto do que a vida pessoal, a vocação e a colocação profissional, esse resultado indica que a qualidade do curso e a percepção dos alunos sobre essa qualidade podem ajudar a reduzir a evasão. Sob essa perspectiva, a IES deve procurar e implementar respostas para as seguintes perguntas: como fazer os alunos perceberem a qualidade do curso? Pode a qualidade do curso ajudar na colocação profissional dos formados? Como melhorar a qualidade dos cursos para que os alunos permaneçam na instituição?

Foi possível analisar, também, alguns aspectos evidenciados pelos alunos que se evadiram. Esses apresentaram maior necessidade de reforços acadêmicos e tendem a falar bem da infraestrutura. Alunos que se evadiram disseram que necessitavam de mais atividades de reforço do que os alunos que permaneceram. Essa relação mostra que a dificuldade de aprendizado dos alunos pode levá-los a desistir do curso. Nesse sentido, as IES podem reduzir a taxa de evasão levando aos alunos atividades e orientações que os auxiliem a aprender. Já a tendência de falar bem sobre a conservação da infraestrutura (limpeza e manutenção) entre os alunos que vieram a se evadir é uma questão a ser aprofundada em estudos futuros.

Interessante notar que a situação financeira dos alunos não mostrou correlação, tanto com a tendência quanto com a real evasão dos alunos. Essa falta de correlação pode ser decorrente do grande número de cursos estudados, com diferentes perfis dos alunos, ou devido ao fato de os alunos carentes, sem condições de pagarem pelas mensalidades, poderem recorrer a bolsas de estudos e de trabalho na própria instituição.

\subsection{Identificação de alunos em risco de evasão}

Após explorar as dimensões, utilizaram-se três métodos para identificar o risco de evasão dos alunos: a) avaliação das respostas do instrumento de 
avaliação; b) processamento estatístico das respostas dos grupos por meio da análise de clusters; e c) processamento analítico por meio de dedução utilizando redes neurais artificiais $\mathrm{RBF}$.

Utilizaram-se as respostas às intenções de continuar os estudos, em que os alunos apontavam dúvidas na continuidade, para formar um grupo macro de risco (4.030 alunos). Lançou-se mão das respostas de alunos que trancaram sua matrícula ou desistiram durante ou ao final do primeiro semestre de 2009 (300 alunos) para fazer o agrupamento por meio da análise de cluster (HAIR JR. et al., 2007) de respostas dos alunos matriculados nos semestres seguintes. Os alunos que se evadiram ficaram todos em um grupo apenas, incluindo respostas de 2.589 alunos categorizados como "em risco". Por último, utilizou-se a rede neural artificial para identificar a propensão à evasão dos alunos dos semestres seguintes, tendo por base as respostas de 300 alunos que se evadiram entre 2009/1 e 2009/2, e mais 300 escolhidos aleatoriamente, que não se evadiram. Classificou-se o risco dos alunos como "sem risco" no caso de nenhuma das técnicas assim os diagnosticaram, e, como "em risco", no caso de a rede neural e/ou a análise de cluster e/ou as respostas à propensão identificarem os alunos nessa situação. Destaca-se que, dois semestres após a identificação, o percentual de evadidos entre os previstos e não previstos foi praticamente idêntico. Isso indica que as causas e a propensão do aluno a se evadir do curso variam com o passar do tempo, sendo importante que a IES realize essa avaliação periodicamente, de preferência a cada semestre.

A Tabela 3 e a Figura 3 detalham a análise das três técnicas de identificação dos alunos em risco (resposta ao questionário, rede neural RBF e análise de cluster) de forma isolada e conjuntamente, pois tenta identificar qual técnica melhor identifica a propensão à evasão. Verifica-se, por meio desta tabela que, entre o número de alunos que discordou parcialmente ou totalmente das questões sobre permanência (4.030), 11,1\% se evadiram no semestre seguinte, ou seja, $53 \%$ dos alunos que se evadiriam no semestre subsequente foram identificados anteriormente.

Entre os alunos identificados, por meio da Rede RBF, como em risco de evasão, $12,3 \%$ se evadiram no semestre seguinte, dos quais $48 \%$ realmente vieram a se evadir naquele semestre. Por esse método, verificou-se que 6,7\% de alunos classificados como sem risco vieram a se evadir.

A análise de cluster identificou 2.589 alunos em risco de evasão, dos quais $13,1 \%$ se evadiram ( $40 \%$ de todos que vieram a se evadir). Por meio do emprego desse método, identificou-se que $7,1 \%$ de alunos classificados como sem risco vieram a se evadir. 
Tabela 3 - Eficiência de cada método na identificação de evasão

\begin{tabular}{|c|c|c|c|c|c|c|c|c|}
\hline \multirow{4}{*}{$\begin{array}{c}\text { Método de } \\
\text { identificação }\end{array}$} & \multirow{3}{*}{\multicolumn{2}{|c|}{$\begin{array}{c}\text { Alunos } \\
2009-2 \\
\text { diagnosticados } \\
\text { como: }\end{array}$}} & \multicolumn{4}{|c|}{ Evadidos } & \multirow{4}{*}{$\begin{array}{c}\text { Eficácia } \\
\text { de } \\
\text { identifi- } \\
\text { cação da } \\
\text { evasão }\end{array}$} & \multirow{4}{*}{$\begin{array}{c}\text { Percentual } \\
\text { de } \\
\text { evadidos } \\
\text { em 2010-1 } \\
\text { que foram } \\
\text { previstos }\end{array}$} \\
\hline & & & \multirow{2}{*}{\multicolumn{2}{|c|}{$\begin{array}{c}2010-1 \\
\text { classificados } \\
\text { como: }\end{array}$}} & \multirow{2}{*}{\multicolumn{2}{|c|}{$\begin{array}{c}2010-2 \\
\text { classificados } \\
\text { como: }\end{array}$}} & & \\
\hline & & & & & & & & \\
\hline & $\begin{array}{c}\text { em } \\
\text { risco }\end{array}$ & $\begin{array}{l}\text { sem } \\
\text { risco }\end{array}$ & $\begin{array}{c}\text { em } \\
\text { risco }\end{array}$ & $\begin{array}{l}\text { sem } \\
\text { risco }\end{array}$ & $\begin{array}{c}\text { em } \\
\text { risco }\end{array}$ & $\begin{array}{c}\text { sem } \\
\text { risco }\end{array}$ & & \\
\hline Sem Propensão & - & 1.442 & - & $4,7 \%$ & - & $2,5 \%$ & - & - \\
\hline $\begin{array}{c}\text { Respostas com } \\
\text { Propensão }\end{array}$ & 4.030 & 4.307 & $11,1 \%$ & $6,9 \%$ & $5,2 \%$ & $4,4 \%$ & 1,13 & $53 \%$ \\
\hline RBF & 3.323 & 5.034 & $12,3 \%$ & $6,7 \%$ & $5,0 \%$ & $4,7 \%$ & 1,26 & $48 \%$ \\
\hline Cluster & 2.589 & 5.768 & $13,1 \%$ & $7,1 \%$ & $5,3 \%$ & $4,5 \%$ & 1,34 & $40 \%$ \\
\hline Cluster + RBF & 1.240 & 7.117 & $19,4 \%$ & $7,1 \%$ & $5,3 \%$ & $3,7 \%$ & 2,18 & $32 \%$ \\
\hline $\begin{array}{l}\text { Propensão + } \\
\text { Cluster + RBF }\end{array}$ & 1.153 & 7.204 & $16,7 \%$ & $7,7 \%$ & $5,2 \%$ & $4,7 \%$ & 1,87 & $26 \%$ \\
\hline
\end{tabular}

Fonte: Dados da pesquisa.

O uso conjunto da análise de clusters e da RBF diagnosticou 1.240 alunos em risco de evasão, dos quais $19,4 \%$ realmente se evadiram (32\% do total de evadidos no semestre seguinte). Entre os não identificados como em risco de evasão, $7,1 \%$ vieram a se evadir.

Já o uso conjunto dos três métodos (Propensão + Cluster + RBF) diagnosticou 1.153 alunos em risco de evasão, dos quais 16,7\% vieram, realmente, a se evadir no semestre seguinte ( $26 \%$ do total de evadidos). Por meio do emprego desse método, foi possível identificar que $7,7 \%$ de alunos classificados como sem risco vieram a se evadir.

O índice de identificação de evasão, indicado na penúltima coluna da Tabela 3, foi desenvolvido para verificar a eficácia do método de identificação do risco de evasão para o semestre seguinte. Para tal, especifica-se o cálculo da eficácia da identificação do risco de evasão (desempenho/esforço), a partir da equação 1:

Número de alunos evadidos e identificados no semestre $1 \quad x$

Número total de alunos evadidos no semestre 1

Total de alunos pesquisados

Alunos classificados em risco

(equação 1)

O método que se apresentou mais eficaz foi a análise pela rede RBF associada à análise de Cluster. Essa análise pode ser utilizada para indicar o grau de risco da evasão e direcionar o foco de esforços para retenção. Outro ponto importante que se verifica ao comparar a Tabela 3 aos índices de 2009/2 é que, 
após o primeiro semestre de 2010 , as prospecções se tornaram similares aos índices de evasão anteriores (3,7\% se evadiram).

\subsection{Resultado de ações de identificação da propensão à evasão}

No que se refere à última questão da pesquisa que necessita ser respondida - identificar os alunos em risco de evasão pode levar a IES a realmente efetuar ações a reduzir a taxa de evasão de seus alunos? - apresentam-se, na Figura 3, os índices de evasão do primeiro semestre, no período de 2005 a 2010, na IES em que se realizou esta pesquisa e a média semestral da evasão do Brasil (publicado até 2009).

No segundo semestre de 2009, efetuou-se o primeiro levantamento dos alunos propensos à evasão e se desenvolveram ações de contato inicial, procurando reduzir a taxa de evasão, historicamente em torno de $10 \%$ ao semestre. Fez-se o repasse das informações sobre os alunos em risco aos respectivos coordenadores de curso, os quais mantiveram contato com esses alunos. Entre as informações, repassadas, encontravam-se as possíveis causas da tendência a se evadirem, com orientações sobre o que a IES faz a respeito de problemas financeiros, sociais, vocacionais, etc.

Figura 3 - Evasão dos alunos de graduação (IES x Brasil)

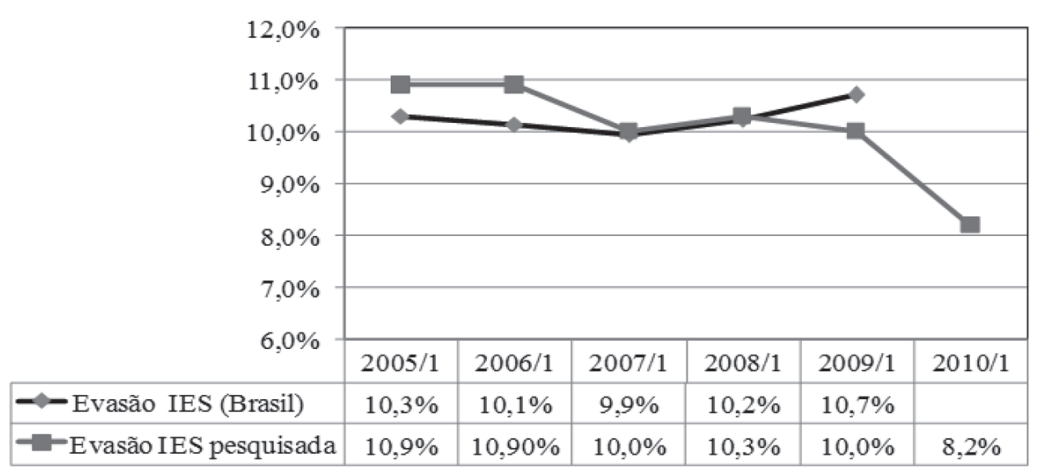

Fonte: INEP. Resumo técnico senso da educação superior de 2009. 2009. Disponível em: $<$ http://download. inep.gov.br/download/superior/censo/2009/resumo_tecnico2009.pdf $>$. Acesso em: 15 jul. 2011.

A receptividade no que tange a essa ação foi positiva, visto que muitos alunos agradeceram e se mostraram felizes pela preocupação demonstrada pela universidade. Alguns chegaram a dizer "obrigado por falar e se preocupar 
comigo". Essa ação de contato com os alunos diagnosticados como em tendência a se evadirem contribuiu para a redução da evasão em $18 \%$ no semestre imediatamente seguinte, diminuindo de $10,3 \%$ para $8,3 \%$ o total de evadidos. Tal redução é estatisticamente significativa, por estar mais de $3 \sigma$ abaixo da média histórica (menos $0,3 \%$ de chances de ser por acaso). Contudo, observa-se que, em virtude dos motivos mudarem com o passar do tempo, essa avaliação necessita ser atualizada periodicamente para obter maior eficácia.

\section{CONSIDERAÇÕES FINAIS}

Tendo em vista a grande concorrência, a estabilização e a possível redução da demanda por cursos superiores, a estratégia para a sobrevivência das IES de direito privado passa pela retenção de seus alunos. Nesse contexto, esse estudo teve por objetivo desenvolver um método de identificação do risco de evasão de alunos de graduação que possibilite evidenciar, prever e diminuir fatores que influenciam risco de evasão dos alunos desses cursos. A partir do método desenvolvido, foi possível identificar os alunos em risco de evasão, os quais foram contatados pelos coordenadores de curso, o que contribuiu para uma redução considerável no índice de evasão. Também se verificaram as dimensões que realmente mais influenciaram a decisão de deixar a instituição: colocação profissional e vocação, dificuldade pessoal em seguir as aulas e tempo para estudo.

Como contribuição teórica deste estudo, destaca-se a identificação de dimensões que se relacionam à decisão de evasão ou permanência e o método desenvolvido, que pode auxiliar no desenvolvimento de novas pesquisas. Assim, sugere-se a aplicação desse método a outras IES para verificar sua adequação a outros contextos, bem como gerar possíveis aperfeiçoamentos.

No tocante às contribuições práticas, aponta-se que, a partir do método apresentado, as IES podem identificar alunos em risco de evasão e, assim, desenvolver estratégias para que esses alunos permaneçam em seus estudos, caso assim desejarem. Como destacado, na IES pesquisada, os coordenadores ficaram encarregados de contatar os alunos em risco de evasão. Contudo, o grande número de alunos classificados como em risco demanda disponibilidade dos coordenadores que, por sua vez, possuem diversas outras atividades a serem desenvolvidas.

A partir dos resultados obtidos neste estudo, é possível apresentar algumas sugestões estratégicas e gerenciais para as IES, que podem auxiliar na redução dos índices de evasão. Em primeiro lugar, estrategicamente é importante que 
a IES tenha em mente que, dada a evolução da pirâmide populacional, existe a tendência de redução no número de ingressantes no primeiro curso de ensino superior. Esse cenário mostra a relevância de procurar manter os alunos que ingressaram na IES.

Ações operacionais, pedagógicas, administrativas e de serviços podem contribuir para a retenção dos alunos. Em primeiro lugar, a IES deveria realizar semestralmente a identificação dos alunos em risco de evasão, pois, em um semestre, pode haver alteração na propensão à evasão. Os resultados apresentados neste estudo mostram que um contato com os alunos em risco de evasão pode fazê-los mudar de opinião, pelo menos temporariamente.

Além do diagnóstico da propensão à evasão, a IES pode utilizar as dimensões citadas neste artigo para auxiliar na permanência. A dimensão de maior impacto foi a vocação do aluno em relação ao curso que está frequentando e à perspectiva de futuro profissional. Nessa dimensão, a IES poderia estruturar um serviço de ajuda à colocação profissional (interface entre empresas e alunos). Se uma empresa necessita de uma pessoa, pode a IES ajudar a localizá-la entre seus alunos? Se um aluno quer começar a trabalhar, saiu ou quer mudar de um emprego, pode a IES ajudá-lo na (re)colocação?

No que concerne à vocação do aluno e sua identificação com o curso que está realizando, a IES poderia reestruturar o currículo do curso, colocando algumas disciplinas práticas no início. Essa ação pode auxiliar o aluno a identificar a profissão que seguirá, como também trazer motivação. Se um aluno sabe que não tem vocação para o curso que está frequentando, a IES pode auxiliá-lo a se transferir para outro com o qual se identifique e que tenha vagas disponíveis?

A dificuldade de alunos de acompanhar as aulas pode estar crescendo devido à facilidade de ingresso no ensino superior. Alunos com menor preparo têm tido mais facilidade de ingresso. Assim, a oferta de aulas de reforço e orientações pedagógicas e técnicas (monitorias) tornam-se cada vez mais importantes para a manutenção dos alunos.

Embora problemas pessoais (de saúde, psicológicos e em casa) estejam fora do controle da IES, essa pode ofertar serviços de orientação psicológica e de saúde aos alunos. Tendo em vista o grande impacto dessa dimensão na evasão, os alunos podem vir a permanecer se tiverem a IES como ponto de apoio.

Por último, e já bastante pesquisado e discutido, está a qualidade do curso. Se os alunos tiverem um bom conceito do curso, as outras dimensões serão afetadas (motivação, empregabilidade, etc.), podendo levar à redução do número de evadidos.

Em relação às limitações da pesquisa, aponta-se que o método e os resultados apresentados necessitam ser reaplicados em outros contextos. 


\section{REFERÊNCIAS}

AAKER, David A.; KUMAR, Vinay; DAY, George S. Pesquisa de marketing. São Paulo: Atlas, 2001.

ALBUQUERQUE, Teresa. Do abandono à permanência num curso de ensino superior. Sísifo - Revista de Ciências da Educação, Lisboa, n. 7, p. 19-28, set./dez., 2008.

ALLEN, Jeff; ROBBINS, Steven B.; CASILLAS, A.; OH, In-Sue. Thirdyear college retention and transfer: effects of academic performance, motivation, and social connectedness. Research in Higher Education, Georgia, v. 49, n. 7, p. 647-664, 2008.

ANJOS NETO, Mário R; MOURA, Alexandre I. Construção de um modelo teórico de marketing de relacionamento para o setor de educação. In: ENCONTRO DA ASSOCIAÇÃO NACIONAL DE PROGRAMAS DE PÓS-GRADUAÇÃO EM ADMINISTRAÇÃO, 28., 2004, Curitiba. Anais... Curitiba: ANPAD, 2004. p. 1-16.

AUGUSTIN, Cristina. Dinâmica das vagas. UERJ. Disponível em: <www2.uerj.br >. Acesso em: 15 jun. 2005.

CABRERA, Alberto F.; NORA, Amaury; CASTAÑEDA, Maria B. The role of finances in the persistence process: a structural model. Research in Higher Education, Georgia, v. 33, n. 5, p. 571-593, 1992.

CISLAGHI, Renato. Um modelo de sistema de gestão do conhecimento em um framework para a promoção da permanência discente no ensino de graduação. 2008. 253f. Tese (Doutorado em Engenharia e Gestão do Conhecimento) - Centro Tecnológico, Universidade Federal de Santa Catarina, Florianópolis, 2008.

CORREA, Ana C. C.; NORONHA, Adriana B.; MIURA, Irene K. Avaliação da evasão e permanência prolongada em um curso de graduação em administração de uma universidade pública. In: SEMINÁRIOS EM ADMINISTRAÇÃO, 7., 2004, São Paulo. Anais... São Paulo: USP, 2004.

DIAS, Ellen C. M.; THEÓPHILO, Carlos R.; LOPES, Maria A. S. Evasão no ensino superior: estudo dos fatores causadores da evasão no curso de Ciências Contábeis da Universidade Estadual de Montes Claros - Unimontes - MG. In: CONGRESSO USP DE INICIAÇÃO CIENTÍFICA EM CONTABILIDADE, 7., São Paulo. Anais... São Paulo: Êxito, 2010. 
DOWD, Alicia C; COURY, Tarek. The effect of loans on the persistence and attainment of community college students. Research in Higher Education, Georgia, v. 47, n. 1, p. 33-62, fev. 2006.

ETZIONI, Amitai. Modern organizations. New Jersey: Prentice-Hal, 1964. HAIR JR, Joseph F.; BABIN, Barry; MONEY, Arthur; SAMOUEL, Phillip. Fundamentos de métodos de pesquisa em administração. Porto Alegre: Bookman, 2005.

HAIR JR, Joseph F. et al. Análise multivariada de dados. 5. ed. Porto Alegre: Bookman, 2007.

HENNIG-THURAU, T.; LANGER, M. F.; HANSEN, U. Modeling and managing student loyalty: an approach based on the concept of relationship quality. Journal of Service Research, Arizona, v. 3, n. 4, p. 331-344, 2001.

HOTZA, Maria A. S. O abandono nos cursos de graduação da UFSC em 1997: a percepção dos alunos-abandono. 86 p. Dissertação (Mestrado em Psicologia) - Centro de Ciências Humanas, Universidade Federal de Santa Catarina, Florianópolis, 2000.

IBGE - Instituto Brasileiro de Geografia e Estatística. Censo 2010: escolaridade e rendimento aumentam e cai mortalidade infantil, 27 de abril de 2012. Disponível em: <www.ibge.gov.br/home/presidencia/noticias/ noticia_visualiza.php?id_noticia $=2125 \& i d \_p a g i n a=1>$. Acesso em: 30 ago. 2012 .

INEP. Resumo técnico senso da educação superior de 2009. 2009. Disponível em: <http://download.inep.gov.br/download/superior/censo/2009/ resumo_tecnico2009.pdf>. Acesso em: 15 jul. 2011.

LEPPEL, Karen. College persistence and student attitudes toward financial success. College Student Journal, Alabama, p. 223-238, 2005.

LEPPEL, Karen. The impact of major on college persistence among freshmen. Higher Education, New York, v. 41, p. 327-342, 2001.

LINKENS, D. A.; NIE, J. Learning control using fuzzified self-organizing radial basis function network. IEEE Transactions on Fuzzy Systems, Taiwan, v. 1, n. 4, p. 280- 287, 1993.

MOODY, John; DARKEN, Christian J. Fast learning in networks of locally tuned processing units. Neural Computation, Cambridge, v. 1, p. 281-294, 1989. 
MORAES, Júlia O. de; THEÓPHILO, Carlos R. Evasão no ensino superior: estudo dos fatores causadores da evasão no curso de Ciências Contábeis da Universidade Estadual de Montes Claros \& UNIMONTES. In: CONGRESSO USP DE INICIAÇÃO CIENTÍFICA EM CONTABILIDADE, 2., 2006. Anais... São Paulo: USP, 2006

OLIVEIRA, João F. de O.; BITTAR, Mariluce; LEMOS, Jardenaide R. Ensino Superior noturno no Brasil: democratização do acesso, da permanência e da qualidade. Revista de Educação Pública, Cuiabá, v. 19, n. 40, p. 201-384, maio/ago. 2010.

PASCARELLA, Ernest T. Student-faculty informal contact and college outcomes. Review of Educational Research, Washington, v. 50, n. 4, p. 545-595, 1980.

ROLLO, Lúcia F.; PEREIRA, Anísio C. Análise do processo educacional contábil sob o prisma de seus elementos de maior relevância. Revista Brasileira de Contabilidade, Brasília, 142, ano 31, p. 49-53, jul./ago., 2003. RUIZ, Valdete M. Motivação na universidade: uma revisão da literatura. Estudos de Psicologia, Campinas, v. 20, n. 2, p. 15-24, maio/ago. 2003. SANTOS, Fabrício F. F. Estudo do Perfil dos Alunos Evadidos da Faculdade de Economia, Administração e Contabilidade - Campus Ribeirão Preto. In: ENCONTRO NACIONAL DA ASSOCIAÇÃO NACIONAL DOS PROGRAMAS DE PÓS-GRADUAÇÃO EM ADMINISTRAÇÃO, 25., 2001, Campinas. Anais... Campinas: ANPAD, 2001.

SILVA FILHO, Roberto L. L.; MOTEJUNAS, P. R.; HIPÓLITO, O.; LOBO, M. B. C. M. A evasão no ensino superior brasileiro. Cadernos de Pesquisa, São Paulo, v. 37, n. 132, p. 641-659, set./dez., 2007.

SPADY, William G. Dropouts from higher education: an interdisciplinary review and synthesis. Interchange, Holanda, v. 1, p. 64-85, 1970.

SPINOSA, M. C. P. Vestibular. Revista da Universidade Federal de Minas Gerais, Belo Horizonte, v. 1, n. 3, ago. 2003.

TINTO, Vicent. Enhancing student persistence: connecting the dots. Wisconsin: The University of Wisconsin, 2002.

TONTINI, Gérson; QUEIROZ, Abelardo A. RBF Fuzzy-ARTMAP: a new neural network for robust on-line learning and identification of patterns. In: IEEE INTERNATIONAL CONFERENCE ON SYSTEMS, MAN AND CYBERNETICS. Proceedings... Beijing, 1996. p. 1364-1369. 